\title{
Assessment of left ventricular contractility during supine exercise in children with left-sided cardiac disease
}

\author{
BRUCE S ALPERT, * KENNETH R BLOOM, † PETER M OLLEY \\ From the Division of Cardiology, Department of Paediatrics, The Hospital for Sick Children, \\ Toronto, Canada
}

SUMMARY Exercise stresses the cardiovascular system and causes it to use its reserve capacities. Exercise assessment may unmask abnormalities of left ventricular contractility not suspected from or detected by resting measurements. We have studied the following indices of left ventricular contractility in 21 children with left-sided congenital heart disease: maximum $\mathrm{dP} / \mathrm{dt}, \mathrm{Vmax}, \mathrm{Vpm}, \mathrm{Vcf}$, and peak meridional wall stress. Studies were performed in the supine posture at rest, and at 25 per cent, and 50 per cent of a predetermined maximal upright workload on a bicycle ergometer. The method of measurement used simultaneous high fidelity catheter pressure tracings and $\mathbf{M}$-mode echocardiography. There were no complications and the technique appeared practical and safe. The measurements of contractility differentiated patients with left ventricular volume or pressure overload from each other and from patients with either volume plus pressure overload, or myocardial dysfunction. These measurements can be used to measure the functional reserve capacity of patients with left-sided lesions, and may be useful in followup studies, especially before and after operation.

Adult studies have shown that exercise may unmask abnormalities of left ventricular contractility not detected at rest. ${ }^{12}$ No such information exists for children. There are few data concerning the assessment of left ventricular contractility at rest in normal children, and in those with congenital heart disease. $^{3-6}$ Computer analysis of high-fidelity catheter pressures readily allows measurement of indices of contractility, such as maximum $\mathrm{dP} / \mathrm{dt}$, Vmax, and Vpm, the normal resting values of which in children have been published..$^{3-5}$ By combining the pressure tracing with a simultaneous $\mathrm{M}$-mode echocardiogram measuring left ventricular volumes, Vcf and peak meridional wall stress may also be calculated. ${ }^{7}$ These indices may be used during exercise to assess the reserve capacity of patients' ventricular functional performance. Though the use of indices of contractility has been questioned, ${ }^{9}$ proponents of other methods of assessment have failed to show any superiority for their techniques.

* Supported by the Ontario Heart Foundation.

†Present address: Division of Cardiology, Department of Medicine, Brooke Army Medical Center, Fort Sam Houston, Texas 78234, USA.

Received for publication 15 May 1980
The purpose of this study was to evaluate the feasibility, safety, and potential value of measuring in this way indices of left ventricular contractility, that is, maximum $\mathrm{dP} / \mathrm{dt}, \mathrm{Vmax}, \mathrm{Vpm}, \mathrm{Vcf}$, and peak meridional wall stress, during supine cycle ergometer exercise in children with left-sided cardiac disease, using this combination of $\mathrm{M}$ mode echocardiogram and high fidelity pressure tracings.

\section{Patients and methods}

Patients were selected from those admitted for routine cardiac catheterisation. The procedure was approved by the Committee on Human Experimentation, The Hospital for Sick Children, and the University of Toronto. Informed written consent was obtained either from the parents or the patient. Patients were included if they were over 7 years of age and had left-sided pressure or volume overload or cardiomyopathy, but had no left-to-right shunt. Twenty-one patients completed the procedure (Table). The haemodynamic or functional abnormalities were as follows: left ventricular pressure overload group $(n=13)$, left ventricular volume overload group $(n=3)$; left ventricular pressure 
plus volume overload group $(\mathbf{n}=3)$; congestive cardiomyopathy $(n=1)$; previous resection of a left ventricular outflow tract obstruction with no residual gradient $(\mathrm{n}=1)$.

Table Clinical data

\begin{tabular}{|c|c|c|c|c|c|}
\hline \multirow{2}{*}{ Group } & & \multirow{2}{*}{$\begin{array}{l}\text { Case } \\
\text { no. }\end{array}$} & \multicolumn{2}{|c|}{ Age (y) } & \multirow{2}{*}{ Diagnosis } \\
\hline & & & Mean & Range & \\
\hline $\begin{array}{l}\text { Pressure } \\
\text { overload }\end{array}$ & $\mathbf{a}$ & $1-6$ & $13 \cdot 5$ & $11-16$ & $\begin{array}{l}\text { Aortic valve or } \\
\text { subvalve stenosis; } \\
\text { trivial or no aortic } \\
\text { regurgitation }\end{array}$ \\
\hline $\begin{array}{l}\text { Volume } \\
\text { overload }\end{array}$ & $\mathbf{a}$ & 14,15 & $15 \cdot 0$ & $14-16$ & $\begin{array}{l}\text { Aortic regurgitation; } \\
\text { systolic gradient } \\
\text { across aortic valve } \\
<20 \text { mmHg } \\
\text { Mitral regurgitation }\end{array}$ \\
\hline \multicolumn{2}{|l|}{$\begin{array}{l}\text { Pressure }+ \\
\text { volume } \\
\text { overload }\end{array}$} & $17-19$ & $12 \cdot 0$ & $8-18$ & $\begin{array}{l}\text { Aortic stenosis plus } \\
\text { significant aortic } \\
\text { regurgitation }\end{array}$ \\
\hline \multicolumn{2}{|c|}{ Cardiomyopathy } & 20 & 19 & - & $\begin{array}{l}\text { Non-obstructive } \\
\text { cardiomyopathy }\end{array}$ \\
\hline \multicolumn{2}{|c|}{ Postoperative } & 21 & 12 & - & $\begin{array}{l}\text { Postoperative } \\
\text { subaortic diaphragm } \\
\text { resection, no } \\
\text { residual systolic } \\
\text { gradient }\end{array}$ \\
\hline
\end{tabular}

The day before catheterisation, each patient underwent a simple upright progressive stress test on an electronically braked cycle ergometer (model AM368, 368, Elema-Schonander, Stockholm, Sweden) as described by Godfrey et al. ${ }^{10}$ The maximum upright workload achieved and maintained for one minute (kilogram metres) was used as the basis for the exercise period during catheterisation. The mean workload achieved was 876 (kg m) \pm 300 (SD) (range 500 to 1400). This workload corresponded to $97 \pm 15$ per cent of that predicted (range 75 to 127 per cent).

On the day of catheterisation the patients were only mildly sedated (meperidine 1.0 to $1.5 \mathrm{mg} / \mathrm{kg}$ and diazepam 0.2 to $0.3 \mathrm{mg} / \mathrm{kg}$ by mouth) in order to be able to perform ergometer exercise. The right antecubital fossa was anaesthetised with 2 per cent xylocaine and catheters were placed in the median basilic vein by cut-down, and in the right brachial artery by the percutaneous technique. After diagnostic haemodynamic data had been obtained, a high fidelity catheter, zeroed to atmospheric pressure, either a twin sensor (one in left ventricle, one in aorta) or single sensor (left ventricle) was placed in position via the brachial artery (Model PC-761 or PC-350, Millar Instruments, Inc.,
Houston, Texas). The zero calibration was repeated after pressure measurements were completed to ensure that no drift had occurred.

Echocardiograms were recorded with a hand-held 0.25 or $0.5 \mathrm{in}, 5 \mathrm{~cm}$ focused, $2.25 \mathrm{MHz}$ transducer (Aerotech, Inc, Lewiston, Pennsylvania) and a Hoffrel Model 101 ultrasonoscope (Hoffrel Instruments, Norwalk, Connecticut), and a Cambridge multichannel recorder (Model 1005, Cambridge Instrument Co, Ossining, New York). The echocardiogram traces during catheterisation were at the level of the left ventricular cavity just below the tips of the mitral valve leaflets. The left ventricular pressure tracing and electrocardiogram were superimposed on the echocardiogram to allow simultaneous analysis of pressure-volume relations (Fig. 1 and 2).
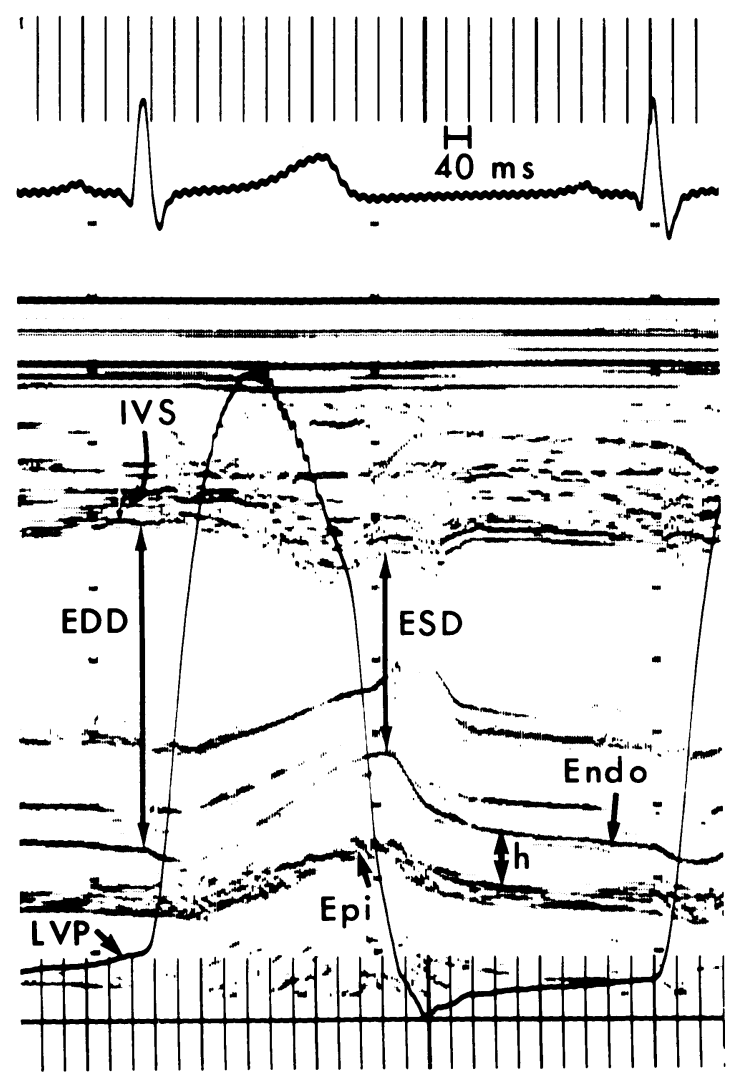

Fig. 1 Simultaneous $M$-mode echocardiogram of the left ventricular ( $L V$ ) cavity, endocardium (endo), and interventricular septum (IVS) with the high-fidelity LV pressure (LVP) superimposed. Arrows show method of measurement of IVS thickness, $L V$ end-diastolic dimension (EDD), end-systolic dimension (ESD), and wall thickness (h). Epi, epicardium. 


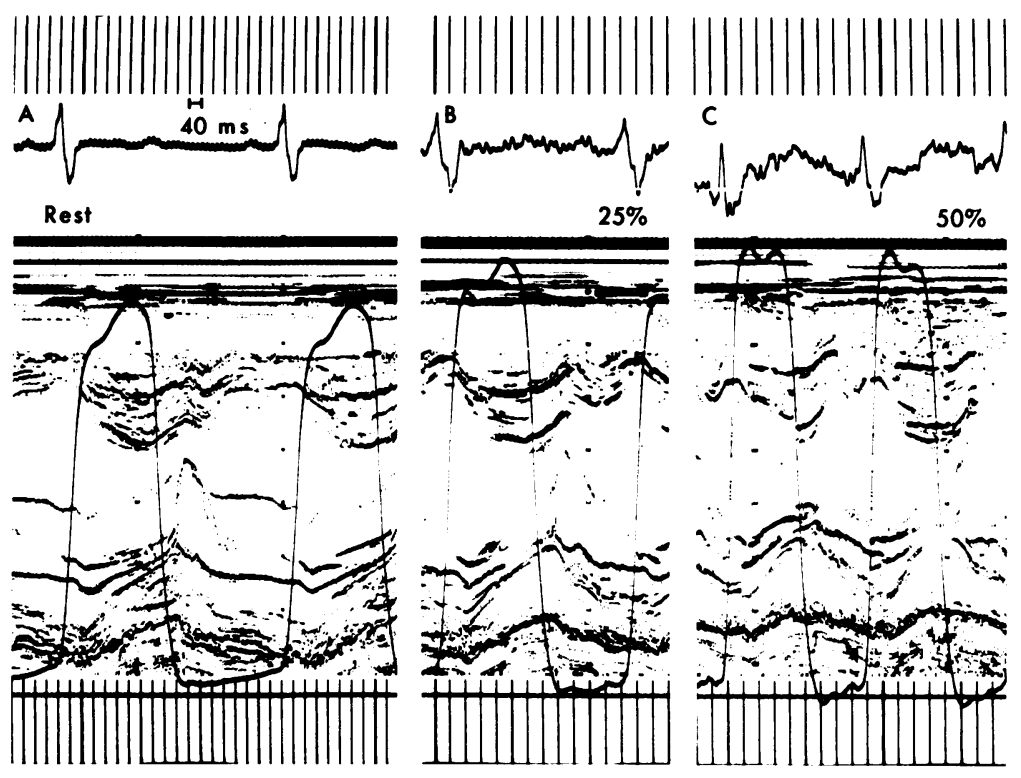

Fig. 2 Echocardiograms and pressure traces with increasing exercise levels in the same patient: (A) at rest; (B) at 25 per cent maximum workload; (C) at 50 per cent maximum workload. For method of measurement, see Fig. 1.

The patient was moved to the caudal end of the catheterisation table for supine exercise. After his feet had been raised into the ergometer pedals (approximately $20 \mathrm{~cm}$ above the level of the catheterisation table, depending on the size of the patient) for at least three minutes, measurements were carried out at rest. These measurements included the maximum value for the first differential of pressure versus time (left ventricular $\mathrm{dP} / \mathrm{dt}$ ), the peak velocity of muscle shortening $(\mathrm{Vpm})$, and the maximum velocity of the contractile element (Vmax) derived from a Hewlett-Packard catheterisation data analysis system, model 5600 . The $\mathrm{dP} / \mathrm{dt}, \mathrm{Vpm}$, and Vmax values from case 16 (mitral regurgitation) were not included because of the lack of an isovolumic contraction period. The computer system calculated $\mathrm{dP} / \mathrm{dt}$ by a differentiator with a $16 \mathrm{~Hz}$ cutoff. Vmax and Vpm were calculated from derived left ventricular pressures as described by Mirsky et al. ${ }^{11}$ with $\mathrm{K}=30$.

From the echocardiographic and pressure recordings, the mean velocity of circumferential fibre shortening (Vcf) and peak meridional wall stress were calculated. The echocardiographic Vcf was calculated as follows:

$$
\frac{\text { LVEDD - LVESD }}{\text { LVEDD } \times \text { LVET }}
$$

where LVEDD = left ventricular end-diastolic dimension, LVESD = left ventricular end-systolic dimension, and LVET $=$ left ventricular ejection time.
The left ventricular ejection time was obtained by computer by simultaneous analysis of heart rate, left ventricular pressure, and aortic pressure. The peak value for meridional wall stress was obtained from the following equation:

meridional wall stress

$$
=\frac{\mathrm{LV} \text { pressure } \times \mathrm{LV} \text { dimension }}{4 \mathrm{~h}(1+\mathrm{h} / \text { dimension })} \times 10^{3} \text { dynes } / \mathrm{cm}^{2} \text {, }
$$

where $h=$ left ventricular endocardial thickness. The necessary variables were measured at $40 \mathrm{~ms}$ intervals and wall stress was calculated; the largest value was equated with peak meridional wall stress.

After the data for each of the above indices had been obtained, the patient began to pedal at 60 revolutions per minute at a workload approximately 25 per cent of the previous day's maximum upright workload. Because of technical limitations, this workload was the nearest $50 \mathrm{~kg} \mathrm{~m}$ multiple. After two and a half minutes were allowed for the achievement of a steady state, the variables were recorded again. After satisfactory data had been collected, the workload was increased to 50 per cent of the maximum upright workload and after two and a half minutes the variables were measured for a third time. After completion of the exercise studies, the patient returned to the cranial end of the catheterisation table for angiography.

\section{STATISTICAL ANALYSIS}

Data were evaluated within clinical groups by analysis of variance. If variance ratios were not 
unequal, then $\mathbf{P}$ values were obtained by either paired or unpaired Student's $t$ test. The data shown in the figures are mean values; no rigorous comparison of variables between groups was made because of the small numbers of patients.

\section{Results}

MAXIMUM DP/DT

The values for maximum $\mathrm{dP} / \mathrm{dt}$ at rest (Fig. 3) showed a small separation, which reflected the patients' haemodynamic abnormalities. The patients with left ventricular pressure overload and pressure plus volume overload had the highest values, while those with left ventricular volume overload and muscle dysfunction had lower values. The responses to exercise showed further separation than at rest. The rise from rest to 25 per cent maximal upright workload and from 25 to 50 per cent was significant $(p<0.01)$ in both the patients with aortic stenosis and those with coarctation.

To allow for differing initial values, the percentage changes from resting measurements were calculated (Fig. 4). The patient with cardiomyopathy (case 20) showed only a small increase from the resting to the 25 per cent level; all other patients had larger increases. At the 50 per cent level, the same case showed a decrease to below the resting value, whereas other patients showed an increase of at least 65 per cent above it.

\section{VPM}

The resting values for Vpm (Fig. 3) were closely grouped. As the exercise level increased there was a wider separation of values, with the increases in the aortic stenosis and coarctation groups significant at the $p<0.02$ and $p<0.001$ level, respectively, for the interval from rest to 25 per cent of maximum upright workload. The small number of values for the 50 per cent level precluded their analysis. Again, patients with left ventricular pressure overload showed the highest values. Analysis by percentage changes from baseline (rest) values (Fig. 4) appeared to increase the separation obtained. The left ventricular volume overload and volume and pressure overload groups, however, had changed places in comparison with their curves of maximum $\mathrm{dP} / \mathrm{dt}$.

\section{VMAX}

As with the previous two indices, values at rest (Fig. 3) were too close to separate the various
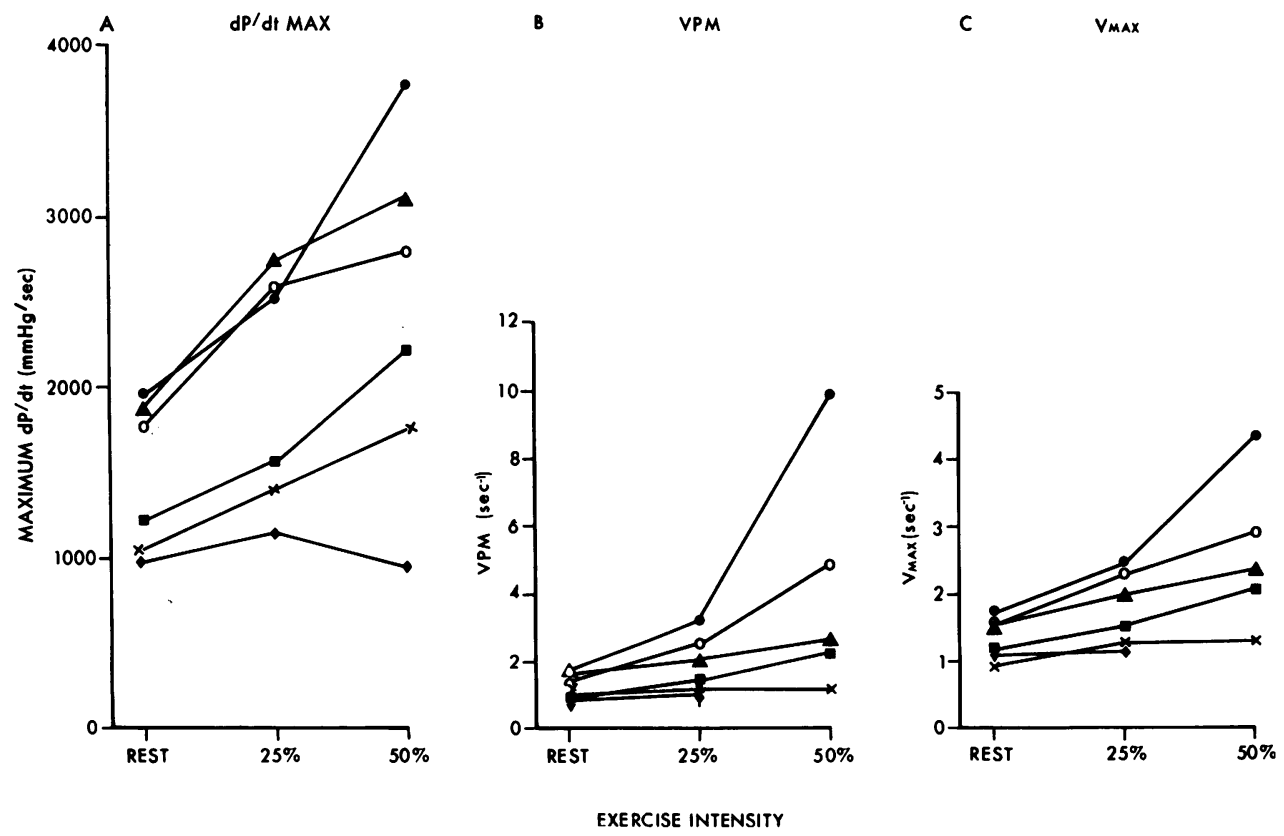

Fig. $3 L V$ pressure-derived indices of contractility with increasing exercise levels: $(A)$ maximum $d P / d t$ $(m m H g / s)$; (B) VPM $\left(s^{-1}\right) ;(C) V \max \left(s^{-1}\right)$. Clinical groups of patients represented by the following symbols: Circles, pressure overload: 0 , aortic stenosis; $O$, coarctation; squares, volume overload :

$\square$, aortic regurgitation; $\Lambda$, volume plus pressure overload; $\diamond$, cardiomyopathy; $\times$, postoperative resection. 

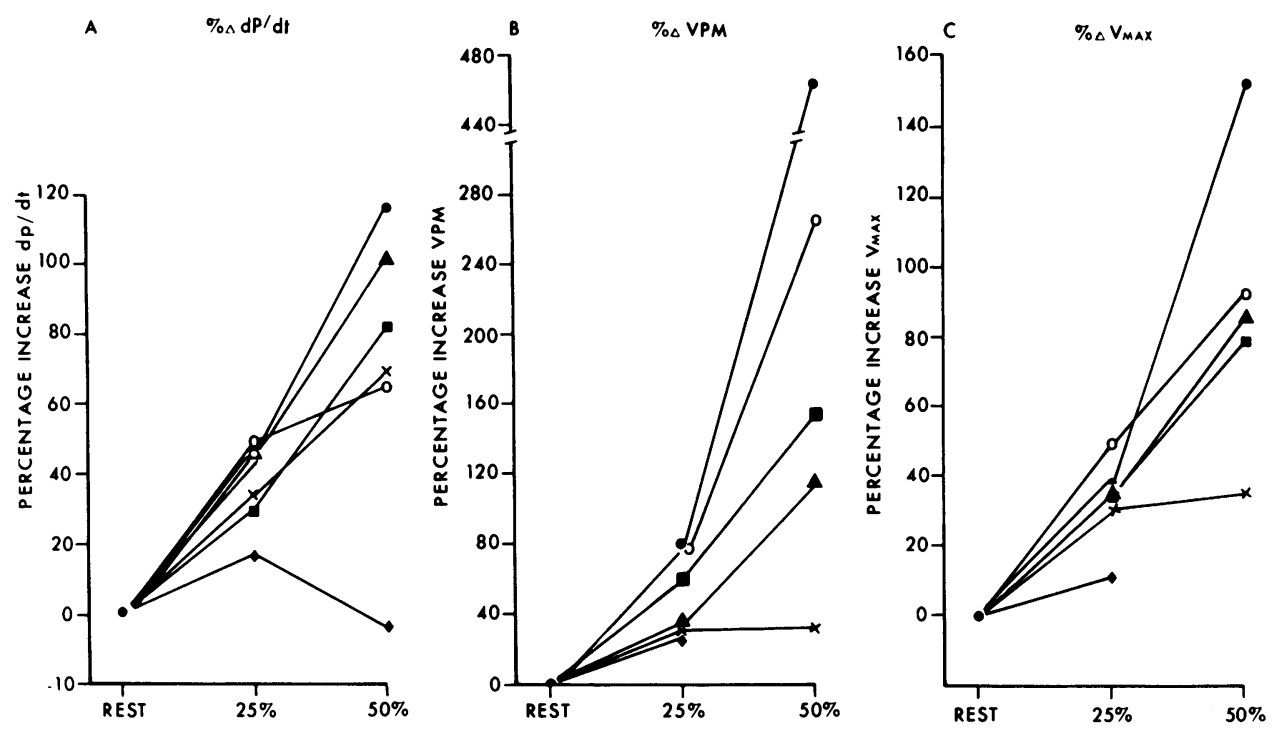

EXERCISE INTENSITY

Fig. 4 Percentage changes ( $\% \triangle)$ from resting values for $L V$ pressure-derived indices of contractility with increasing exercise intensity: (A) maximum $d P$; $d$; (B) VPM; (C) Vmax. Symbols as in Fig. 3.

haemodynamic groups reliably. The increase from rest to 25 per cent of maximum upright workload was significant in both pressure overload groups $(\mathrm{p}<0.01$ (aortic stenosis) and $\mathrm{p}<0.001$ (coarctation)). The rise in the intensity of exercise led to the same pattern of values as with Vpm. The patients with left ventricular pressure overload had the highest values; those with combined pressure plus volume overload intermediate values, and those with left ventricular volume overload or muscle dysfunction the lowest values. The percentage change plot (Fig. 4) failed to add further specificity.

VCF

The values from all patients except case 20 showed almost linear responses with increasing exercise levels (Fig. 5). The patient with cardiomyopathy (case 20) showed a transient increase, followed by a fall below baseline at the 50 per cent level. This pattern was similiar to his data for $\mathrm{dP} / \mathrm{dt}$.

The patient with mitral regurgitation, whose values for $\mathrm{Vpm}, \mathrm{dP} / \mathrm{dt}$, and Vmax could not be included because of the lack of an isovolumic contraction period, had a Vcf response which closely resembled the two other patients with left ventricular volume overload.

PEAK MERIDIONAL WALL STRESS

The values of peak meridional wall stress (Fig. 5) varied widely at rest, but at 50 per cent of maximal upright workload, the patients within subgroups became very similar. The patients with pressure overload maintained relatively low values for peak wall stress with increasing exercise intensity, while those with left ventricular volume overload con-

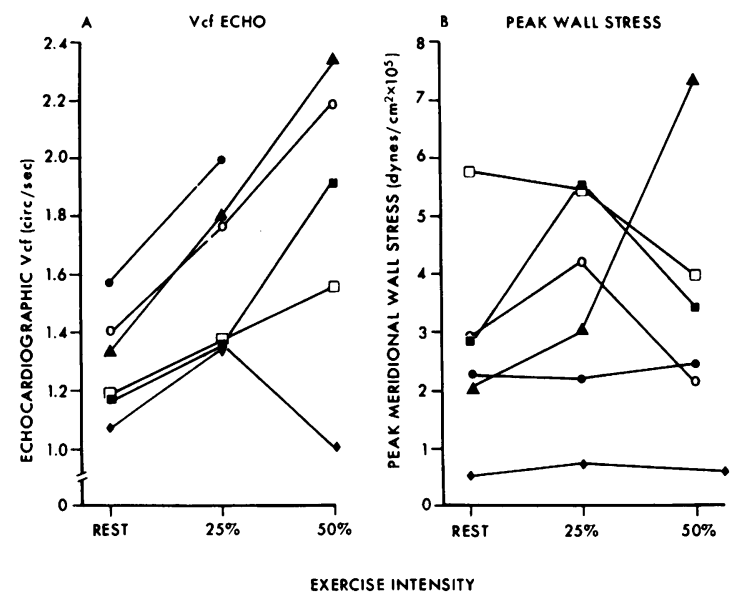

Fig. 5 Echocardiographic and LV pressure-derived indices of contractility plotted against increasing exercise levels: (A) Vcf (circ/s); (B) peak meridional wall stress (dynes $/ \mathrm{cm}^{2} \times 10^{5}$ ). Symbols as in Fig. 3, with the addition of $\square$, the patient with mitral regurgitation. 
sistently maintained higher levels of peak wall stress. The combination of left ventricular pressure and volume overload did not give intermediate values as with Vmax, Vpm, and maximum $\mathrm{dP} / \mathrm{dt}$, the haemodynamic disturbances appearing to be additive, giving this group the highest values of peak wall stress. The large increase in this group occurred in association with increased left ventricular end-diastolic pressure, and decreased oxygen supply : demand ratio. The myocardium in case 20 maintained low peak wall stress values. This was associated with an unchanged systolic blood pressure and lower than expected cardiac output with exercise.

\section{Discussion}

The purpose of this study was to investigate the feasibility, safety, and potential value of a combined high-fidelity catheter and echocardiographic technique to assess left ventricular contractility during supine ergometer exercise in children with leftsided cardiac lesions. This was carried out in 21 patients, in none of whom were there complications related to the presence of the catheter in the left ventricle during exercise. While the number of patients is still small, the technique appears safe, and may provide valuable additional information which will be helpful in the assessment of the functional reserve capacity of the left ventricle in children either before or after operation.

\section{CONTRACTILITY INDICES AT REST:}

MAXIMUM DP/DT, VPM, VMAX

There are few data available concerning left ventricular contractility indices in children with congenital heart disease. Graham et al. ${ }^{3}$ established normal values for maximum $\mathrm{dP} / \mathrm{dt}, \mathrm{Vpm}$, and $\mathrm{Vmax}$. Jarmakani et al. ${ }^{4}$ extended the use of these indices to patients with successfully corrected ventricular septal defects. The theoretical assumptions that must be made in order to calculate these variables include: (1) that an isovolumic contraction period exists, (2) that left ventricular geometry does not change during this contraction, and (3) that there is relative independence of these variables from preload and afterload. In our study, we did not include the values for $\mathrm{dP} / \mathrm{dt}, \mathrm{Vpm}$, and Vmax in a patient with mitral regurgitation because of the lack of a true isovolumic contraction period. For the same reason, patients with aortic regurgitation might also be excluded, but it has been suggested that contractility indices are valid unless aortic regurgitation is severe ${ }^{12}$ and in support of this, in our patients with this lesion, angiographic regurgitation diminished considerably near end-diastole, and probably was minimal during the initial phase of contraction. In contrast, the indices $\mathrm{Vpm}$ and peak wall stress do not depend on an isovolumic contraction period, but are still dependent on geometric considerations. $^{8}$

The normal value for maximum $\mathrm{dP} / \mathrm{dt}$ is $1410 \pm 50$ $\mathrm{mmHg} / \mathrm{s}^{4}$ Our patients with pressure overload and pressure plus volume overload had values higher than this (Fig. 3). The $\mathrm{dP} / \mathrm{dt}$ values in the left ventricular volume overload group and in cases 20 and 21 were below normal, similar to Jarmakani's patients with ventricular septal defect and unobstructed right ventricular outflow. Our findings may confirm Jarmakani's suggestion that the volume-overloaded left ventricle has impaired contractility.

The normal value for $\mathrm{Vpm},{ }^{4} 1.30 \pm 0.05 / \mathrm{s}$, was exceeded at rest by the left ventricular pressure and pressure plus volume overload patients (Fig. 3). Again, the patients with volume overload, as well as those with congestive cardiomyopathy (case 20) and postoperative left ventricular outflow obstruction (case 21), had decreased values, in the same range as Jarmakani's patients with volume overload.

The values for Vmax for our patients with pressure overload were at or only slightly above the normal value, ${ }^{4} 1.50 \pm 0.09 / \mathrm{s}$, derived from total left ventricular pressure (Fig. 3). The other patients had lower values, similar to the decreases shown for maximum $\mathrm{dP} / \mathrm{dt}$ and $\mathrm{Vpm}$.

\section{EXERCISE RESPONSES:}

MAXIMUM DP/DT, VPM, VMAX

There are no data for normal children during exercise for any of the left ventricular indices of contractility measured. Because of the availability of sophisticated non-invasive precatheter assessments, that is $\mathrm{M}$-mode and cross-sectional echocardiography, we have not catheterised any patients with trivial heart disease or none at all.

Our patient with cardiomyopathy had the greatest impairment of left ventricular function of all those studied; his ability to increase contractility in response to supine exercise was limited (Fig. 3 and 4). Previous reports of exercise studies in healthy volunteer adults have shown increases in contractility during isotonic exercise, ${ }^{13} 14$ and impairment in contractility in patients with acquired left ventricular dysfunction. ${ }^{12}$ We might expect that the increases in each of the other groups of patients is the more normal response. Whether, in fact, the patients with pressure overload, many of whom had a hypercontractile angiographic appearance, had exercise values for maximum $\mathrm{dP} / \mathrm{dt}, \mathrm{Vpm}$, and Vmax which were above normal cannot be assessed as yet. In previous studies, patients with left ven- 
tricular hypertrophy had impaired contractility at rest $^{15-17}$ and this may not persist during isotonic exercise; the added muscle mass may permit higher pressures and flows to occur in response to peripheral demand.

\section{ECHOCARDIOGRAPHIC-DEPENDENT INDICES AT REST: VCF, PMWS}

Each group of patients showed a separation of Vcf values consistent with that predicted from their haemodynamics. Vcf, however, has been shown to vary with rate and age. ${ }^{1819} \mathrm{~A}$ value of $1.34 \pm 0.03$ circ/s has been considered normal for patients in this age group. ${ }^{20}$ Only our patient with cardiomyopathy (Fig. 4) had a value below that $(1.07 \mathrm{circ} / \mathrm{s})$. The assumption that changes in contractility are reflected by changes in Vcf can only be valid if the change in heart rate after an intervention has been taken into account. We did not recalculate Vcf values for each patient because heart rates did not differ widely in our patients.

Peak meridional wall stress has been investigated in adults ${ }^{7}{ }^{8}$ but in only a few children. ${ }^{6}$ The advantages of using an echocardiographic assessment of peak meridional wall stress include: the absence of the depressive effects of contrast material, the lack of any need to assume the long axis measurement, and the ease with which preoperative and postoperative measurements may be compared, measurements which are not dependent on the placing of epicardial markers. We observed neither eccentric left ventricular hypertrophy nor regional asynergy in any of our patients. There is evidence ${ }^{8}$ that peak meridional wall stress may be a more sensitive indicator of ventricular contractility than circumferential wall stress. The reason for this is related to the assumptions concerning ventricular geometry. Circumferential wall stress calculations vary as the left ventricle assumes a more spherical shape with deteriorating function. So far there have been no studies in children on changes in peak meridional wall stress with different congenital heart lesions. There are data from normal children at rest, however. The peak meridional wall stress values in nine patients were $1.52 \pm 0.47$ dynes $/ \mathrm{cm}^{2} \times$ $10^{5}$ (mean $\pm \mathrm{SD}$ ), with a range of 0.8 to 2.31 (Lee Benson, 1979, unpublished observations). The values in our patients at rest (Fig. 5) were either at the upper end of or above the normal range, with the exception of the patient with cardiomyopathy. His wall stress value was low because of low pressures and a slightly enlarged but extremely hypertrophied left ventricle.

EXERCISE RESPONSES: VCF, PMWS

All patients except the one with cardiomyopathy showed almost linear, parallel increases in echo- cardiographic Vcf with exercise. The patients with left ventricular pressure overload had the highest Vcf values both at rest and with increasing exercise intensity. The patient with cardiomyopathy had a similar increase to the 25 per cent level of maximum upright workload but then an abrupt fall to below the baseline value at the 50 per cent level. This indicates a very poor functional reserve. We are unaware of any exercise Vcf data in normal children with which to compare those from our patients. It seems reasonable to expect that as rate increases, with decreased left ventricular ejection time, slightly smaller ventricular dimensions, and an increased ejection fraction, ${ }^{13} \mathrm{Vcf}$ would increase, but without normal data, we cannot judge whether these patients with left-sided cardiac abnormalities had a high, low, or normal Vcf response.

With increasing exercise intensity, the peak meridional wall stress values showed considerable variation. The peak exercise peak wall stress values of the patients with left ventricular pressure overload were similar to their resting values, suggesting good functional reserve of left ventricular contractility. The patients with left ventricular volume overload had the highest values at 25 per cent of maximum upright workload, indicative of haemodynamic changes which lead to a larger left ventricular volume overload in the absence of appropriate pressure and wall thickness changes necessary to normalise peak wall stress. The patients with left ventricular volume plus pressure overload had a striking increase in peak meridional wall stress with increasing exercise intensity. The left ventricular end-diastolic pressure rose with exercise and oxygen supply demand ratios of these patients had become abnormal, ${ }^{21}$ so that this rise in peak wall stress clearly reflected the impaired left ventricular contractility present during exercise. Since these patients had among the lowest values for resting peak meridional wall stress, exercise unmasked abnormal left ventricular function which could not have been otherwise predicted. The lack of increase in peak meridional wall stress in the patient with cardiomyopathy was unexpected. His left ventricular end-diastolic pressure rose considerably with exercise and each of the other indices studied suggested that his left ventricular contractility was the worst of all of the patients studied. Possibly it was so impaired that the myocardium was unable to respond to peripheral demands and that he incurred a large metabolic debt by the use of anaerobic metabolism.

\section{Conclusions}

We have used a combined high-fidelity catheter 
and echocardiographic technique to assess left ventricular contractility in 21 children during supine exercise which appears to be of potential value in the pre- and postoperative assessment of the functional reserve capacity of the left ventricle of children with left-sided cardiac disease. There were no complications; we consider the technique practical and safe. Because of the relatively few patients within each subgroup and the lack of agematched controls, the value of it cannot yet be accurately assessed. We were able to unmask responses which deviated from those theoretically expected. The studies were effected by a physiological intervention, that is exercise; no alteration in haemodynamics was introduced by the measuring process itself.

\section{References}

1 Mason SJ, Weiss JL, Weisfeldt ML, Garrison JB, Fortuin NJ. Exercise echocardiography: detection of wall motion abnormalities during ischemia. Circulation 1979; 59: 50-9.

2 Bussmann WD, Mayer V, Kober G, Kaltenbach M. Ventricular function at rest, during leg raising and physical exercise before and after aortocoronary bypass surgery. Am f Cardiol 1979; 43: 488-93.

3 Graham TP Jr, Jarmakani JM, Canent RV Jr, Anderson PAW. Evaluation of left ventricular contractile state in childhood. Normal values and observations with a pressure overload. Circulation 1971; 44: 1043-52.

4 Jarmakani JM, Graham TP Jr, Canent RV Jr. Left ventricular contractile state in children with successfully corrected ventricular septal defect. Circulation $1972 ; 45$ \& 46, suppl 1: I-102-I-110.

5 Mirsky I, Ellison RC, Hugenholtz PG. Assessment of myocardial contractility in children and young adults from ventricular pressure recordings. $A m \mathcal{F}$ Cardiol 1971 ; 27: 359-67.

6 Benson L, Bloom K, Williams C, Olley P, Rowe R. Echographic and hemodynamic evaluation of left ventricular function in children (abstract). $A m \mathcal{F}$ Cardiol 1979; 43: 365.

7 Brodie BR, McLaurin LP, Grossman W. Combined hemodynamic-ultrasonic method for studying left ventricular wall stress. Comparison with angiography. Am f Cardiol 1976; 37: 864-70.
8 Gould KL, Lipscomb K, Hamilton GW, Kennedy $\mathrm{JW}$. Relation of left ventricular shape, function and wall-stress in man. Am $\mathcal{f}$ Cardiol 1974; 34: 627-34.

9 Elzinga G, Westerhof $\mathrm{N}$. How to quantify pump function of the heart. The value of variables derived from measurements on isolated muscle. Circ Res 1979; 44: 303-8.

10 Godfrey S, Davis CTM, Wozniak E, Barnes CA. Cardiorespiratory response to exercise in normal children. Clin Sci Mol Med 1971; 40: 419-31.

11 Mirsky I, Dhanjoo N, Sandler H. Cardiac mechanics: physiological, clinical and mathematical considerations. New York: John Wiley, 1974: 87-112 \& 293-329.

12 Yang SS, Bentivoglio LG, Maranthao V, Goldberg H. Assessment of ventricular function. In: From cardiac catheterization data to hemodynamic parameters. Philadelphia: F A Davis, 1978: 284-5.

13 Mitchell JH. Mechanisms of adaption of the left ventricle to muscular exercise. Pediatrics 1963; 32: 660-70.

14 Sarnoff SJ, Mitchell JH, Gilmore JP, Remensnyder JP. Homometric autoregulation in the heart. Circ Res 1960; 8: 1077-91.

15 Rackley CE. Quantitative evaluation of left ventricular function by radiographic techniques. Circulation 1976; 54: 862-79.

16 Gunther S, Grossman W. Determinants of ventricular function in pressure-overload hypertrophy in man. Circulation 1979; 59: 679-88.

17 Krayenbeuhl HP, Rutishauser W, Wirz P, Amende I, Mehmel $\mathrm{H}$. High-fidelity left ventricular pressure measurements for the assessment of cardiac contractility in man. Am F Cardiol 1973; 31: 415-27.

18 Fisher EA, DuBrow IW, Hastreiter AR. Comparison of ejection phase indices of left ventricular performance in infants and children. Circulation 1975; 52: $916-25$.

19 Gutgesell HP, Paquet M, Duff DF, McNamara DG. Evaluation of left ventricular size and function by echocardiography. Results in normal children. Circulation 1977; 56: 457-62.

20 Goldberg SJ, Allen HD, Sahn DJ. Pediatric and adolescent echocardiography. Chicago: Year Book Medical Publishers, 1975: 65.

21 Hoffman JIE. Determinants and prediction of transmural myocardial perfusion. Circulation 1978; 58: 381-91.

Requests for reprints to Dr Bruce S Alpert, Section of Pediatric Cardiology, The Medical College of Georgia, Augusta, Georgia 30912, USA. 